\title{
An Assessment Approach to Urban Economic Resilience of the Rust Belt in China
}

\author{
Shan Man, ${ }^{1,2}$ Xiangli Wu $\mathbb{D}^{2}{ }^{2}$ Yongchun Yang, ${ }^{1,3}$ and Qingmin Meng ${ }^{4}$ \\ ${ }^{1}$ College of Earth and Environmental Sciences, Lanzhou University, Lanzhou 730000, China \\ ${ }^{2}$ College of Geographical Science, Harbin Normal University, Harbin 150025, China \\ ${ }^{3}$ Key Laboratory of Western China's Environmental Systems, Ministry of Education of the People's Republic of China, \\ Lanzhou University, Lanzhou 730000, China \\ ${ }^{4}$ Department of Geosciences, Mississippi State University, Mississippi State, Starkville, MS 39762, USA
}

Correspondence should be addressed to Xiangli Wu; jndxwxl@163.com

Received 13 May 2021; Revised 28 July 2021; Accepted 15 August 2021; Published 10 September 2021

Academic Editor: Xiuliang Yuan

Copyright (c) 2021 Shan Man et al. This is an open access article distributed under the Creative Commons Attribution License, which permits unrestricted use, distribution, and reproduction in any medium, provided the original work is properly cited.

Urban economic resilience provides a novel perspective on the sustainable development of urban and regional economy. Selecting 37 prefecture-level cities in the Northeast China that also known as the rust belt in China as a regional study sample that has experienced significant economic decline and out-migration in the last 20 years compared to many other regions in China, this study aims to construct an index system using the data collected in 2005, 2010, and 2016. This study evaluates urban economic resilience including five socioeconomic aspects: diversity, capabilities related to revenue and expenditure, innovation environment, trend of development, and openness. We analyze the spatial and temporal evolution characteristics of urban economic resilience, explore the key factors contributing to urban resilience and then provide decision-making suggestions to enhance it. We find the following: (1) urban economic resilience in the Northeast China has gradually increased over time, but spatial heterogeneity of resilience was prominent. Specifically, coastal cities were more economically resilient than inland cities. (2) Urban economic resilience in the Northeast China is significantly contributed by the diversity of an economic system and the trend of development, which contribute to resilience with weights of 0.214 and 0.216 , respectively. The dominant factors contributing to urban economic resilience are different among diverse urban economic types and size. (3) To enhance urban economic resilience, comprehensive economic cities need to focus on increasing the diversity of economic structures. Resourcebased and old industrial cities should focus on raising the innovation environment. Coastal cities should focus on increasing the diversity of their economic structures and creating positive trends of economic and social development. Agricultural cities should focus on creating positive trends of economic and social development.

\section{Introduction}

Cities across the world are facing chronic pressure and acute shock nowadays from many perspectives, such as the ecological, social, economic, and environmental challenges. Scientists and urban managers have carried out relevant research and emergency work, and the construction of resilient cities is one of the important benchmarks [1]. Typically, there are four main backgrounds for the rise of resilient cities: first, at the ecological level, climate, geological disasters, and ecological deterioration have led to increasing urban emergencies. Extreme weather such as global warming, frequent ice disasters, and heavy rain seriously threatens the development of cities. Second, at the economic level, since the 2008 Western financial crisis, the global economy has been sluggish, urban unemployment has increased significantly, and factory closures and large-scale strikes have become frequent, which all call for the urban economy to shift from relying on only service industries to a diversified economy. Third, at the social level, the uncertainty of urban development has become a common problem in all countries in the world. The uncertainty faced by most cities is exacerbated by the instability of the natural, societal, economic, and political environment. Fourth, at the 
planning level, a goal of urban planning is to deal with uncertainty and regulate the healthy development of the city [2].

With the acceleration of globalization, the economic systems of different countries are often subject to various shocks, such as economic cycle fluctuations, policy adjustments, financial crises, and technological innovations. The development of urban economic system becomes more difficult to predict due to these social, economic, and environmental fluctuations. Facing the increasing regional and global markets' threats and opportunities, the resilience assessments that cities should take to maintain the stable and healthy development of economic systems become a grand challenge, which is more challenging for declining urban areas such as the Northeast China, which is the typical rust belt in China [3]. Urban economic resilience has gradually become a hot issue for scholars nationally and internationally.

Northeast China is the cradle of China's industry, including the three provinces of Liaoning, Jilin, and Heilongjiang and the eastern part of Inner Mongolia (Figure 1). Before the reform and opening up, the state-owned economy in Northeast China occupied a dominant position, played an important role in Chinese economic development progress, and was the foundation of China's industrial economic development. Northeast China has provided strong support for the rapid development of its economy. After the Reform and Opening Up policy in 1978, resource-exhausted cities appeared owing to the excessive exploitation and use of resources in resource-based cities, and the developmental momentum of cities in Northeast China gradually weakened. In general, cities in the Northeast China have low economic resilience and are easily affected by the economic crisis and other shocks. Moreover, as China's traditional old industrial basis, the economic recession and revival of Northeast China is of great significance to the development of the country and region. Urban economic resilience provides a new perspective for analyzing the economic revitalization of old industrial bases. Studying the characteristics and main contributing factors of urban economic resilience of the old industrial bases in Northeast China is of great significance for exploring the path of improving urban economic resilience of old industrial bases and realizing a fresh round of economic revitalization. Therefore, it is necessary to study the urban economic resilience of Northeast China [4].

However, since the implementation of the market economy system, a series of problems have emerged in the economic development of Northeast China. Although the implementation of China's Northeast revitalization strategy has improved the economic strength and social development level of cities in Northeast China, the economic development of Northeast China still encountered such problems as a lack of development power, weak urban agglomeration, and difficulties in transforming resource-based cities. The economic growth rate in Northeast China is gradually lagging behind the national average. In general, urban economic resilience in Northeast China still has the characteristics of fragility [5]. Therefore, under the background of the prominent urban economic problems in Northeast China, this study established the index system of urban economic resilience, which is conducive to improving the research on the index system of urban economic resilience in China. Moreover, this study clarified the main contributing factors of urban economic resilience, which can provide a basis for the coordinated development of cities in Northeast China.

At the same time, the index system established in this study can also be used as a reference for scholars in other developing countries to study urban economic resilience and help them find the factors that contribute the most to urban economic resilience. In addition, the policy conclusions of this study can provide reference for the economic development of the old industrial areas in other countries.

\section{Literature Review}

The concept of "resilience" was first applied to ecology [6] and subsequently to geography [7], economics [8], and sociology $[9,10]$. Research on urban resilience began once the concept of resilience was extended from social-ecological systems to urban systems. The concept also has been widely used in the agricultural and biological environmental sciences [11-13], psychology [14], and energy engineering $[15,16]$. In addition to the research on the concept of urban resilience, scholars have also carried out abundant research on its characteristic elements [17], research content framework [18], and evaluation system [19]. The research scope has been extended to different levels, such as individuals and communities [20]. Among them, urban economic resilience is an important perspective of urban resilience research, and it is the deepening of urban resilience research in the economic aspect. Based on prevalent research [21-25], it is defined as the ability of the urban economic system to maintain and promote its long-term economic development, responding to cyclical economic crises, increased competitors, unexpected company closures, and technological changes. Generally, four manifestations of urban economic resilience under external shocks and disturbances have been identified [26]: (1) a restoration to the stable state before the disturbance; (2) the maintaining of some functions and structures, and moving to a substable state; (3) the failure to maintain the stability of structures and functions, and gradually declining; and (4) the readjusting of its structure and function according to the situation after the disturbance, and then moving to another developmental state. Currently, research on the evaluation of urban economic resilience includes means of measuring resilience [27-29] and discovering factors influencing it $[30,31]$.

Research on resilience in China started later than that in the West. With the accelerating process of urbanization, the number of uncertain factors and unknown risks facing the country's complex urban system is increasing, and intensive research on urban resilience is thus underway. Different fields have different emphasis on resilience research, but the consensus among them is to use it to study the response of an object to external changes or interference [32]. The global financial crisis of 2008 led to "economic resilience" emerging 


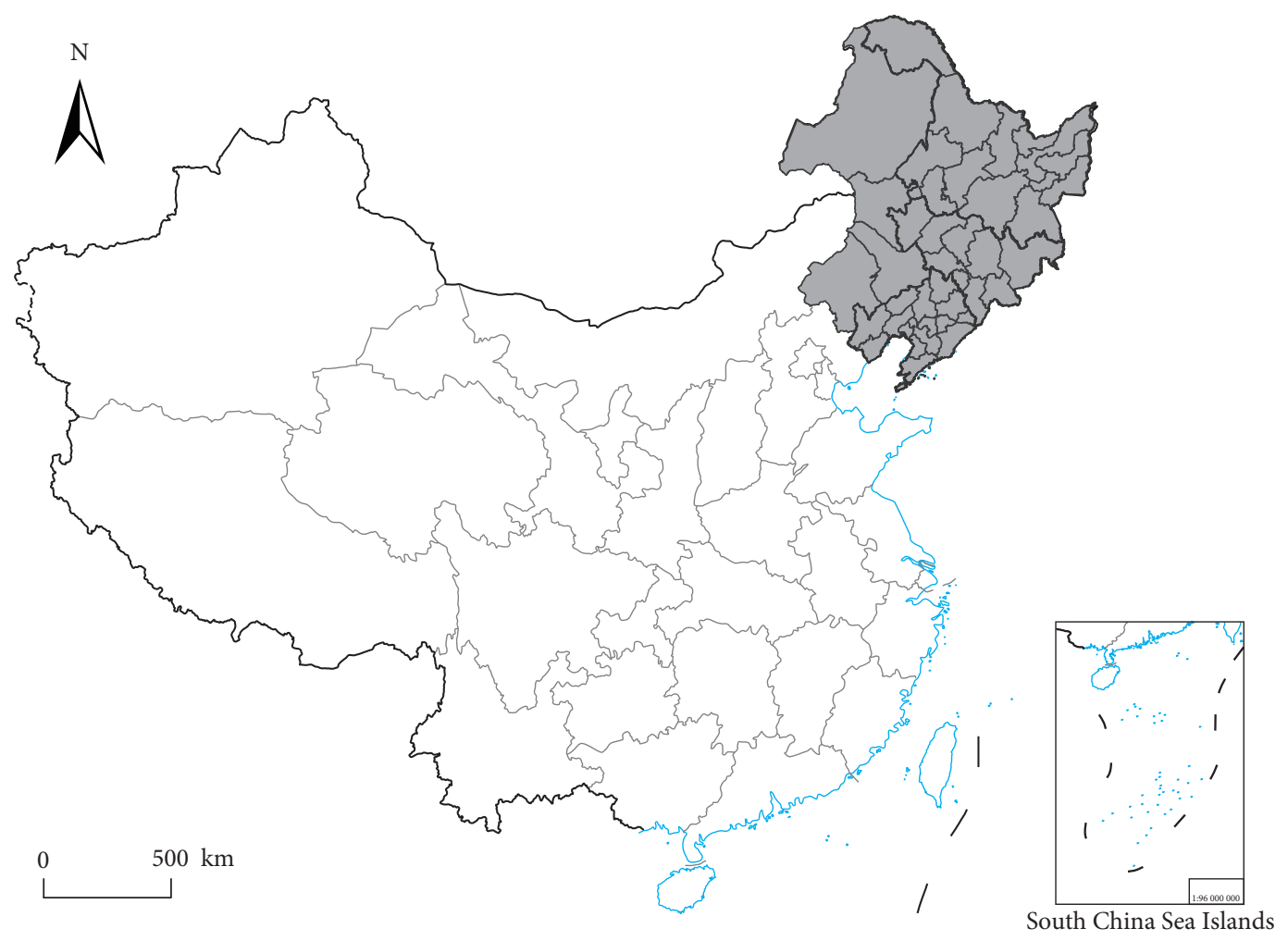

Northeast China

Figure 1: The location of Northeast in China.

as the focus of research on urban resilience. Scholars thus began exploring methods to measure it, especially quantitatively. Current research on urban economic resilience is mainly related to four aspects: (1) using the concept of resilience to guide urban planning and design [33, 34], (2) the exploration of concepts and theories related to urban resilience $[35,36],(3)$ the design of index systems for the evaluation of urban economic resilience [37-39] and its factors influencing it $[40,41]$, and (4) studies of the economic resilience of special types of cities [42, 43].

Although research has contributed significantly to the theory and practice of urban economic resilience, critical issues still need to be explored and revealed. First, the concept of urban economic resilience has penetrated into urban and regional development and management, but there is not a standard theoretical system available for regional urban systems. Second, although many scholars have attempted to build measurement systems for urban economic resilience, no commonly practicable index systems are available for regional assessment. Further research on evaluating urban economic resilience is thus needed. Third, the spatial and temporal scales of urban economic resilience are poor, and the spatial and temporal scales' exploration will provide deep reveals of it. At last, regional resilience assessment in rust belt regional has not been studied, which is an important social and economic issue in both developed and developing countries. To the best of our knowledge, this study is the first research to regionally and temporally assess urban economic resilience in a developing country. How to measure urban economic resilience is an important issue in current urban development research. Many studies have comprehensively measured the spatial and temporal characteristics of urban resilience by constructing a multidimensional and multistage evaluation system $[27,28,37,38]$, but few focus on the economic perspective to measure urban economic resilience. Moreover, the existing studies on urban economic resilience do not classify the types of cities.

In view of the above, this study enriches and complements the research in this field, and we constructed an evaluation index system of urban economic resilience from five socioeconomic aspects: diversity, capabilities related to revenue and expenditure, innovation environment, trend of development, and openness, and used multi-indicator comprehensive evaluation method to measure the spatiotemporal evolution characteristics of urban economic resilience in 37 cities of the rust belt of China. Then, we classified the cities in Northeast China into comprehensive economic cities, resource-based and old industrial cities, coastal cities, and agricultural cities, analyzed the factors contributing to the economic resilience of these four types of cities, and obtained the factors contributing to the economic resilience of different types of cities. Therefore, this study not only enriches the research on the index system of urban economic resilience in developing countries but also diversifies the types of cities studied. It also provides strategical decisions for sustainable development of rust belt cities in China. 


\section{Data and Methods}

3.1. Study Area and Data. The research object of this paper was the prefecture-level cities in Northeast China (i.e., the rust belt in China). We studied 37 prefecture-level cities, excluding the Yanbian Korean Autonomous Prefecture, Da Hinggan Ling Prefecture, Hinggan League, and Xilingol League because of unavailable data. The data were drawn mainly from the China City Statistical Yearbook, China City Construction Statistical Yearbook, Regional Economic Statistical Yearbook, the statistical yearbooks of the relevant provinces and cities, economic census yearbooks, and statistical bulletins in 2005, 2010, and 2016. If the data of a factor are missed, we use the average value of the related records in the previous and the following years to interpret correspondingly.

3.2. The Resilient Assessment Index System. The evaluation index of urban economic resilience is a conceptual expression of the causes and mechanisms of urban economic resilience. Each index system or conceptual model is trying to find the root cause of resilience. It mainly involves sustainable development theory, system synergy theory, vulnerability theory, and so on. Sustainable development theory focuses on guiding the sustainable and healthy development of the urban economy. System synergy theory emphasizes the coordinated development of the various subsystems of the urban economy, thereby promoting overall urban development. High resilience is related to low vulnerability, so resilience can be interpreted in depth according to vulnerability theory.

Currently, the representative urban resilience evaluation system comes from the resilient city framework index system proposed by the Rockefeller Foundation, which is based on four types of index systems: health and well-being, economy and society, infrastructure and environment, leadership, and strategy [44]. And some scholars have proposed a framework for evaluating community resilience based on the Rockefeller Foundation's index system. This framework consists of four parts: external resources, assets, capabilities, and qualifications [45]. In addition, the Regional Research Institute of the State University of New York released an evaluation system for resilience to respond to rapid population growth, economic recession, and natural disasters in metropolitan areas, which is mainly composed of 12 indicators in three dimensions: regional economic capacity, society-population, and community connectivity. Some scholars also constructed a $4 \mathrm{R}$ evaluation index system based on the three aspects of society-politics-technology, economy, and nature, with the four characteristics of robustness, redundancy, resourcefulness, and rapidity [27]. Moreover, some scholars also use the interview method, questionnaire survey method, and other methods to construct evaluation models for evaluating urban resilience $[28,46]$.

Compared with the existing research, the evaluation index system in this paper makes the original research on urban resilience more pertinent. The evaluation index system established in this paper is based on the urban resilience evaluation system and conducts in-depth research on its economic resilience. It divides the economic resilience index system into five subsystems: diversity, capabilities related to revenue and expenditure, innovation environment, trend of development, and openness. On the one hand, it can make the evaluation results of economic resilience more accurate, thereby helping to make targeted suggestions for the optimization of urban economic resilience in Northeast China; on the other hand, it can improve the economic resilience evaluation index system and improve the scientificity of the measurement system.

By referring to the available index systems for the evaluation of urban economic resilience [24, 25, 34, 35], we adopted principles based on five aspects of an economic system including diversity, capabilities related to revenue and expenditure, innovation environment, trend of development, and openness, in combination with physical and geographical conditions, historical bases, and policy-related advantages of Northeast China to determine initial indices. We then consulted ten experts in human geography, regional economics, urban geography, and ecology to screen and initialize indices and then determine the final evaluation indices. The experts are scholars in the field of resilience and vulnerability research. We used the importance and availability of indicators as selection principles, and the retention and deletion of the index is based on $1 / 3$ of the number of experts. When no less than $1 / 3$ of the experts think the index needs to be adjusted, the index will be retained or deleted. Finally, the retained indicators are summarized into Table 1, which forms a hierarchical indexing assessment system including five system levels, 11 criterion levels, and 30 factor levels.

For the diversity system: the diversified development of an urban economy can enhance the ability of the urban economy to resist cyclical economic crisis. If one aspect of the economy goes wrong, other aspects can continue to support the development of the city. Therefore, the improvement of urban economic diversity can enhance urban economic resilience. The concept of economic diversity is usually equated with industrial diversity when studying urban economic diversity. Therefore, we selected the structural diversity index for primary, secondary, and tertiary industry and the structural diversity index for 19 subsectors in primary, secondary, and tertiary industry to represent the industrial diversity, and we selected the proportion of the tertiary industry as percentage of GDP to represent the ability of industrial transformation and upgrading, so as to measure the diversity of the urban economy from the aspects of industrial diversity and transformation and upgrading ability.

For the capabilities related to revenue and expenditure system: revenue and expenditure capacity is an important index to measure the living standard of residents. Urban revenue and expenditure capacity includes the revenue and expenditure capacity of individual residents and government public finance. The revenue and expenditure of public finance have the function of adjustment. It can relieve the unreasonable distribution phenomenon and realize social equity. Therefore, revenue and expenditure capacity in this 
TABLE 1: An index system to assess urban economic resilience in the rust belt of China.

\begin{tabular}{lll}
\hline System level & Criterion level & Specific factor level (formula)
\end{tabular}

C1 structural diversity index for primary, secondary, and tertiary industry (the specific algorithm is detailed in Section 3.3.1)

A1 diversity

B1 industrial diversity

B2 industrial transformation and upgrade

B3 personal revenue- and expenditure-related ability

A2 capabilities related to revenue and expenditure

B4 governmental revenue and expenditure ability

B5 technological innovation environment

A3 innovation environment

B6 ecological development environment

B7 basic social environment

B8 economic development trend

A4 trend of development
C2 structural diversity index for 19 subsectors in primary, secondary, and tertiary industry (the specific algorithm is detailed in Section 3.3.1)

C3 tertiary industry as percentage of GDP (tertiary industry output/ gross domestic product)

C4 per capita GDP (gross domestic product/population)

C5 per capita disposable income ((total household income-income tax paid-social security expenditure paid by individual-accounting subsidy)/family population)

C6 per capita household saving deposits rate (household saving deposits at year-end/gross domestic product/population)

$\mathrm{C} 7$ public fiscal revenue as percentage of GDP (public finance income/ gross domestic product)

C8 public fiscal expenditure as percentage of GDP (public finance expenditure/gross domestic product)

C9 science and technology expenditure as percentage of public fiscal expenditure (expenditure for science and technology/public finance expenditure)

C10 per 10,000 people subscribers of Internet services (number of subscribers of Internet services/population/10000)

C11 per 10,000 people patent applications (number of patent applications/population/10000)

C12 per 10,000 people scientific papers (number of scientific papers/ population/10000)

C13 per capita public recreational green area (public recreational green area/population)

C14 green coverage of built district (green coverage area/built area) C15 ratio of industrial solid wastes comprehensive utilized (number of utilized industrial solid wastes/total number of industrial solid wastes)

C16 per 10,000 people full-time teachers in regular institutions of

higher education (number of full-time teachers in regular institutions of higher education/population/10000)

C17 per 10,000 people doctors (number of doctors/population/10000) C18 proportion of education expenditure in fiscal expenditure (expenditure for education/public finance expenditure)

C19 GDP growth rate ((gross domestic product of the next year-gross domestic product of the previous year)/gross domestic product of the previous year $* 100 \%)$

C20 investment in focused assets growth rate ((investment in focused assets of the next year-investment in focused assets of the previous year)/investment in focused assets of the previous year $* 100 \%$ )

C21 total value of social retail goods growth rate ((total value of social retail goods of the next year-total value of social retail goods of the previous year)/total value of social retail goods of the previous

$$
\text { year } * 100 \%)
$$

C22 natural population growth rate ((population of the next yearpopulation of the previous year)/population of the previous year $* 100$ )

C23 employment growth rate ((employment of the next yearemployment of the previous year)/employment of the previous

B9 social development trend

$$
\text { year * 100) }
$$

C24 social security and employment expenditure as percentage of fiscal expenditure (expenditure for social security and employment/public finance expenditure) 
TABle 1: Continued.

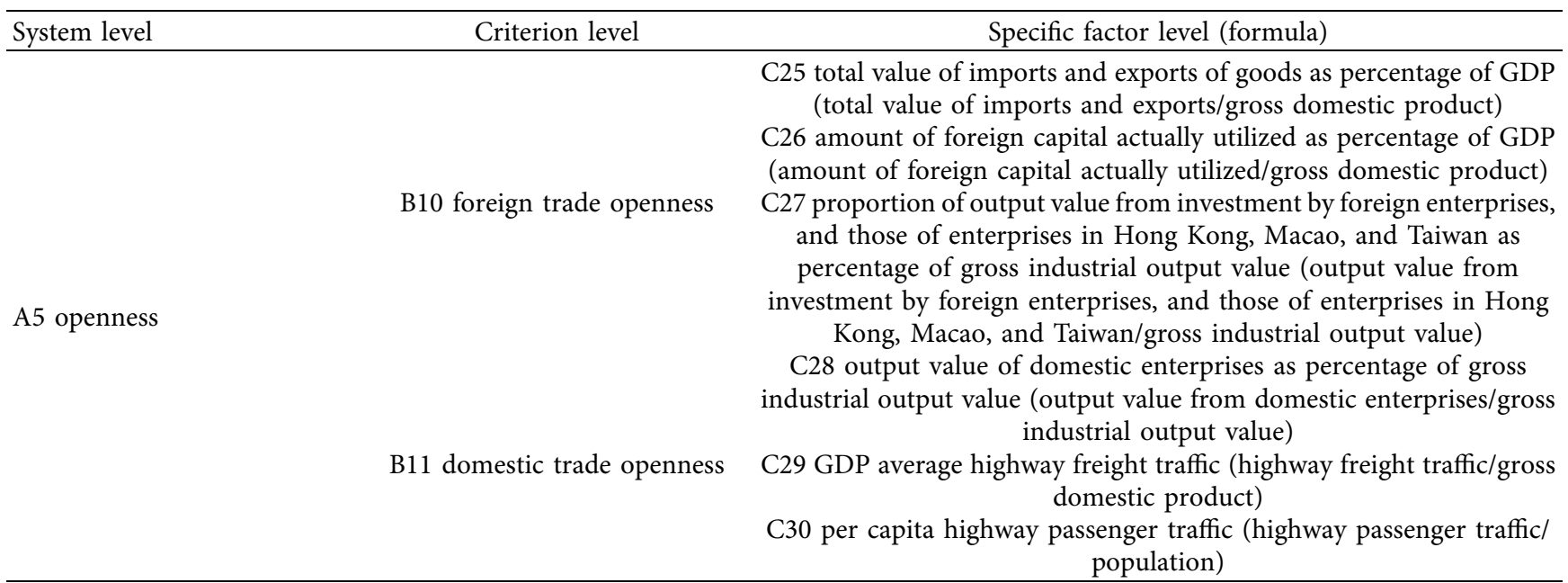

study mainly consists of two aspects. One is personal revenue and expenditure ability, including per capita GDP, per capita disposable income, and per capita household savings deposits rate. The other is governmental revenue and expenditure ability, including public fiscal revenue as percentage of GDP and public fiscal expenditure as percentage of GDP.

For the innovation environment system, innovation environment influences the transformation of the regional economic growth model. The improvement of the innovation environment is conducive to the progress of science and technology, thus promoting the growth of the regional economy and improving the sustainable development ability of urban economy. Therefore, the improvement of the innovation environment is conducive to enhancing urban economic resilience. We selected three important indicators of innovation environment: one is technological innovation environment, including science and technology expenditure as percentage of public fiscal expenditure, per 10000 people subscribers of Internet services, per 10000 people patent applications, and per 10000 people scientific papers. Two is ecological development environment, including per capita public recreational green area, green coverage of built district, and ratio of industrial solid wastes comprehensive utilized. Three is basic social environment, including per 10000 people full-time teachers in regular institutions of higher education, per 10,000 people doctors, and the proportion of education expenditure in fiscal expenditure.

For the development trend system, the development trend system mainly reflects the law, speed and trend of urban development, and can also predict the future development direction of a city. Only by understanding the direction of future development can we better withstand the unknown risks. The development trend of this study mainly includes two aspects. One is economic development trend, including GDP growth rate, investment in focused assets growth rate, and total value of social retail goods growth rate. The other is social development trend, including natural population growth rate, employment growth rate, and social security and employment expenditure as percentage of fiscal expenditure.

For the openness system, increasing the openness of the economic system will increase the flow of resources. The more open the regional economy is, the higher the level of economic development will be, and the stronger the economic resilience will be. Under the development trend of economic globalization, enhancing the openness of the economic system has become the main development direction of the world economy. We selected two aspects of openness. One is foreign trade openness, including total value of imports and exports of goods as percentage of GDP, amount of foreign capital actually utilized as percentage of GDP and proportion of output value from investment by foreign enterprises, and those of enterprises in Hong Kong, Macao, and Taiwan as percentage of gross industrial output value. The other is domestic trade openness, including output value of domestic enterprises as percentage of gross industrial output value, GDP average highway freight traffic, and per capita highway passenger traffic.

\subsection{Assessment Approaches}

3.3.1. Shannon Index. We used the Shannon index to measure the value of $\mathrm{C} 1$ and C2 (Table 1). Suppose the total number of employees in a city is $A$; $A$ is then divided into " $n$ " types of industries according to the economic activities that they engage in. The employees in various industries are $A_{i}(1,2,3, \ldots, n)$; then, $\sum_{i=1}^{n} A_{i}=A$. According to the formula for Shannon's entropy, the informational entropy of the industrial structure is defined as

$$
H=-\sum_{i=1}^{n} P_{i} \ln P_{i}=-\sum_{i=1}^{n}\left(\frac{A_{i}}{\sum_{i=1}^{n} A}\right) \ln \left(\frac{A_{i}}{\sum_{i=1}^{n} A_{i}}\right),
$$

where $H$ is the value of the industry's structural diversity index and $P_{i}$ is the proportion of employees in various industries. 
3.3.2. Entropy Method. We used the entropy method to give weights to the indicators of the specific index level and the system level. It is mainly a measure of uncertainty in the state of the system. The higher the entropy is, the more balanced is the system's structure, and the smaller the difference in indices. The lower the entropy is, the more unbalanced the system structure is, and the larger the difference in indices:

$$
\begin{aligned}
& e_{j}=-k \sum_{i=1}^{m} y_{i j} \ln \left(y_{i j}\right), k=\frac{1}{\ln m}, 0 \leq e_{j} \leq 1 \\
& \omega_{j}=\frac{\left(1-e_{j}\right)}{\sum_{i=1}^{n}\left(1-e_{j}\right)},
\end{aligned}
$$

where $e_{j}$ is the informational entropy of the index, $y_{i j}$ is the standardized value of the index, $\omega_{j}$ is its weight, $m$ is the number of samples, and $n$ is the number of indices in the specific index level.

\subsubsection{Multi-Index Comprehensive Evaluation Method.} We use the multi-index comprehensive evaluation method to measure urban economic resilience by weighting resilience and summing it.

First, the value of each subsystem's resilience is calculated by

$$
t=\sum_{i=1}^{m} a_{i} \cdot \omega_{i}, \quad i=1 \ldots, l,
$$

where $t$ is the value of the resilience of each subsystem, $a_{i}$ is the standardized value of index $i$ at the specific index level, $\omega_{i}$ is the weight of index $i$ at the specific index level of each system, and $l$ is the number of specific indices of each system level.

Then, we calculate the value of urban economic resilience:

$$
T=\sum_{j=1}^{n} t_{j} \cdot W_{j}, \quad j=1 \ldots, z,
$$

where $T$ is the value of urban economic resilience, $t_{j}$ is the value of the resilience of subsystem $j$ at the system level, $W_{j}$ is its weight, and $z$ is the number of indices in the system level.

\section{Temporal and Spatial Characteristics}

Applying the above methods, we obtained the urban economic resilience of the 37 prefecture-level cities in Northeast China. The results are summarized in Table 2.

4.1. Temporal Evolution Characteristics. On the whole, urban economic resilience in Northeast China gradually increased from 2005 to 2016 (Table 2). Its average value was 0.300 in 2005, 0.318 in 2010, and 0.340 in 2016. Growth from 2005 to 2010 was smaller than that from 2010 to 2016 . This is mainly because the total economic output of cities in Northeast China has achieved continuous growth since implementing the strategy of revitalizing the old industrial base in Northeast China. However, due to the different levels of development at each stage, it shows stage characteristics. The period from 2005 to 2007 was in the early stage of implementation of the strategy, and the economic growth rate of cities in Northeast China was slow. In 2007, Northeast China's economy only accounted for $8.4 \%$ of the country's total. In addition, from 2007 to 2009, the global financial crisis struck, and some major natural disasters occurred, such as the snow disaster during the Spring Festival transport in Northeast China. Due to the impact of natural disasters and other related factors, the average growth rate of urban economic resilience in Northeast China from 2005 to 2010 was relatively small. With the assistance of national policies and self-adjustment, the economic growth of Northeast China has accelerated in 2010. By 2012, Northeast China's economy accounted for $8.8 \%$ of the country's total, reaching the highest proportion since the implementation of the strategy. Since 2013, China has paid more attention to regional economic development and improved its national development strategy based on local conditions. Therefore, the average growth rate of urban economic resilience in Northeast China from 2010 to 2016 was relatively large.

The temporal evolution of urban economic resilience (Table 2) shows that Dalian was the most economically resilient and Suihua was the least in 2005, 2010, and 2016. As a coastal city, Dalian is a main economic, industrial, and tourism hub in the northeastern and eastern China. It has prominent geographical advantages, a good living environment, high economic diversity, and a high degree of internationalization. Since the Reform and Opening Up, it has developed rapidly and has been less affected by the sluggish economic development of Northeast China. Therefore, Dalian had the highest urban economic resilience among cities in the region. Suihua, located in the hinterland of the Songnen Plain, is an important agricultural city with a large-scale base for commodity grain production. The proportion of agriculture here was much higher than the average levels of the country and those of Heilongjiang Province. It has few leading enterprises in industrial development, and the developmental system of its service industry is incomplete. This has led to low per capita GDP. Thus, Suihua was the least economically resilient of the cities in Northeast China.

Cities with declining resilience include Hulun Buir, Siping, Liaoyuan, Baishan, Jixi, Hegang, Yichun, and Mudanjiang. The largest decline in urban economic resilience was Mudanjiang, mainly due to its eight forestry bureaus. In the past decade, the transformation of forestry has been difficult, and the tourism industry has been severely restricted by seasons, which has led to a large loss of population, so the urban economic resilience has declined the most.

Cities with increasing resilience include Chifeng, Tongliao, Shenyang, Dalian, Anshan, Fushun, Benxi, Dandong, Jinzhou, Yingkou, Fuxin, Liaoyang, Tieling, Huludao, Changchun, and so on. The largest increase in urban economic resilience was Changchun, because Changchun has been relying on industries such as automobiles, agricultural 
TABle 2: Values of urban economic resilience in Northeast China in 2005, 2010, and 2016.

\begin{tabular}{|c|c|c|c|c|c|c|c|}
\hline City (abbreviation) & 2005 & 2010 & 2016 & City (abbreviation) & 2005 & 2010 & 2016 \\
\hline Chifeng (CF) & 0.233 & 0.231 & 0.297 & Siping (SP) & 0.221 & 0.202 & 0.218 \\
\hline Tongliao (TL) & 0.285 & 0.288 & 0.291 & Liaoyuan (LYu) & 0.255 & 0.229 & 0.222 \\
\hline Hulun Buir (HB) & 0.401 & 0.328 & 0.363 & Tonghua (TH) & 0.277 & 0.253 & 0.330 \\
\hline Shenyang (SY) & 0.508 & 0.512 & 0.637 & Baishan (BS) & 0.278 & 0.289 & 0.275 \\
\hline Dalian (DL) & 0.564 & 0.642 & 0.644 & Songyuan (SYu) & 0.245 & 0.222 & 0.262 \\
\hline Anshan (AS) & 0.293 & 0.334 & 0.371 & Baicheng (BC) & 0.232 & 0.213 & 0.241 \\
\hline Fushun (FS) & 0.281 & 0.303 & 0.302 & Harbin (HBi) & 0.398 & 0.432 & 0.548 \\
\hline Benxi (BX) & 0.273 & 0.342 & 0.351 & Qiqihar (QQH) & 0.332 & 0.315 & 0.332 \\
\hline Dandong (DD) & 0.296 & 0.329 & 0.362 & Jixi (JX) & 0.312 & 0.326 & 0.282 \\
\hline Jinzhou (JZ) & 0.319 & 0.345 & 0.366 & Hegang (HG) & 0.280 & 0.293 & 0.253 \\
\hline Yingkou (YK) & 0.294 & 0.350 & 0.358 & Shuangyashan (SY) & 0.257 & 0.303 & 0.288 \\
\hline Fuxin (FX) & 0.287 & 0.298 & 0.288 & Daqing (DQ) & 0.338 & 0.335 & 0.405 \\
\hline Liaoyang (LY) & 0.302 & 0.339 & 0.362 & Yichun (YC) & 0.249 & 0.283 & 0.244 \\
\hline Panjin (PJ) & 0.355 & 0.439 & 0.398 & Jiamusi (JMS) & 0.307 & 0.355 & 0.339 \\
\hline Tieling (TLi) & 0.259 & 0.297 & 0.268 & Qitaihe (QTH) & 0.207 & 0.235 & 0.288 \\
\hline Chaoyang (CY) & 0.226 & 0.230 & 0.276 & Mudanjiang (MDJ) & 0.396 & 0.391 & 0.345 \\
\hline Huludao (HLD) & 0.239 & 0.295 & 0.332 & Heihe $(\mathrm{HH})$ & 0.246 & 0.330 & 0.272 \\
\hline Changchun (CC) & 0.359 & 0.336 & 0.519 & Suihua (SH) & 0.177 & 0.195 & 0.200 \\
\hline Jilin (JL) & 0.321 & 0.334 & 0.455 & Average value & 0.300 & 0.318 & 0.340 \\
\hline
\end{tabular}

products processing, and equipment manufacturing for stable and rapid development. In recent years, it has been actively developing emerging industries and attracting investment around the pillar industries and emerging industries mentioned above, so the urban economic resilience has increased the most.

4.2. Characteristics of Spatial Distribution. The spatial distribution of urban economic resilience in the rust belt of China had a gradient distribution of "high in the east and low in the west." By 2016, low urban economic resilience areas were mainly concentrated in small cities in the middle of Heilongjiang and southwestern Jilin, which have a lower economic ranking and slower development speed. High urban economic resilience areas were mainly concentrated in large cities with high economic rankings and faster development speed.

In terms of the urban economic resilience index in the Northeast China, the trend of "high in the east and low in the west" reflects that the overall urban economic resilience in the eastern coastal areas was higher than that in the western inland areas. In 2005, the overall urban economic resilience of Northeast China was relatively low, and that of Suihua, Qitaihe, Siping, Chaoyang Baicheng, and Chifeng was very weak. By 2010, after the financial crisis and natural disasters, with the assistance of national policies and self-adjustment, the economic growth in the Northeast region has accelerated. Although the spatial differentiation of urban economic resilience still exists, the number of cities with low economic resilience has significantly decreased, especially the economic resilience of cities in the eastern part of the Northeast China has grown rapidly. Since then, countries and regions have paid more and more attention to regional economic development. Therefore, urban economic resilience in Northeast China grew rapidly from 2010 to 2016, and low economic resilience areas were mainly concentrated in central Heilongjiang and southwestern Jilin.
We used ArcGIS software to classify urban economic resilience in Northeast China. The region was divided into four levels according to resilience: worse resilience, low resilience, medium resilience, and high resilience (Figure 2). In 2005 (Figure 2(a)), 27 cities in Northeast China had worse and low resilience levels, which were distributed widely in each province. Ten cities had medium and high resilience levels. In 2010 (Figure 2(b)), 19 cities had worse and low economic resilience, mainly distributed in northwestern Heilongjiang Province, western and southern Jilin Province, and northwestern Liaoning Province. 18 cities had medium and high resilience levels and were mainly distributed in eastern Heilongjiang, central Jilin, and southeastern Liaoning. In 2016 (Figure 2(c)), 18 cities had worse and low economic resilience in Northeast China, mainly distributed in central Heilongjiang, southwest Jilin, western and northern Liaoning, and eastern Inner Mongolia. 19 cities had medium and high resilience levels, mainly distributed in southeast Heilongjiang, central Jilin, and southeast Liaoning.

From 2005 to 2016, the number of cities with worse and low economic resilience gradually decreased and that of cities with medium and high economic resilience gradually increased in the region. Economic resilience of cities at low levels of economic development, such as Liaoyuan, Siping, Baicheng, Suihua, and Yichun, remained low while that of cities at medium levels of economic development, such as Dalian and Shenyang, remained medium. The overall distribution was "high in the east and low in the west."

\section{Contribution of Each Subsystem and Promote Suggestions}

The assessment of urban economic resilience is a complex system, and the contribution of each subsystem, including its contribution to urban economic resilience, is different in different cities. The greater the contribution of the subsystem is, the more likely it is to become the main factor that affects 


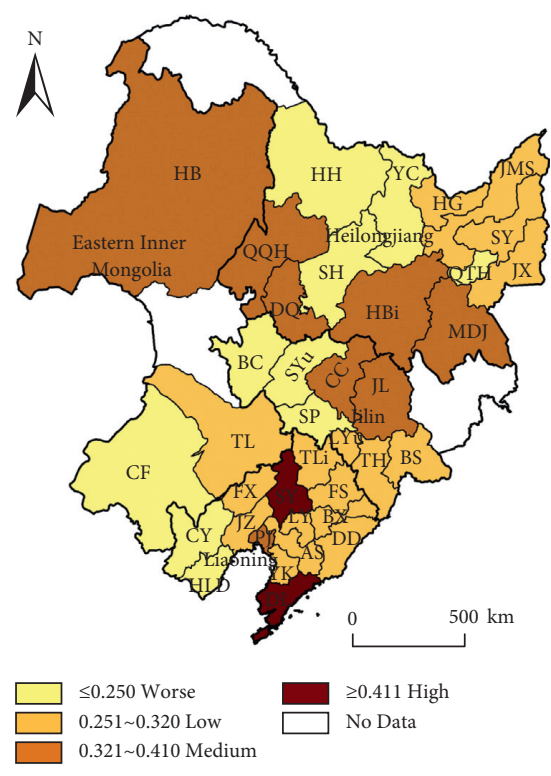

(a)

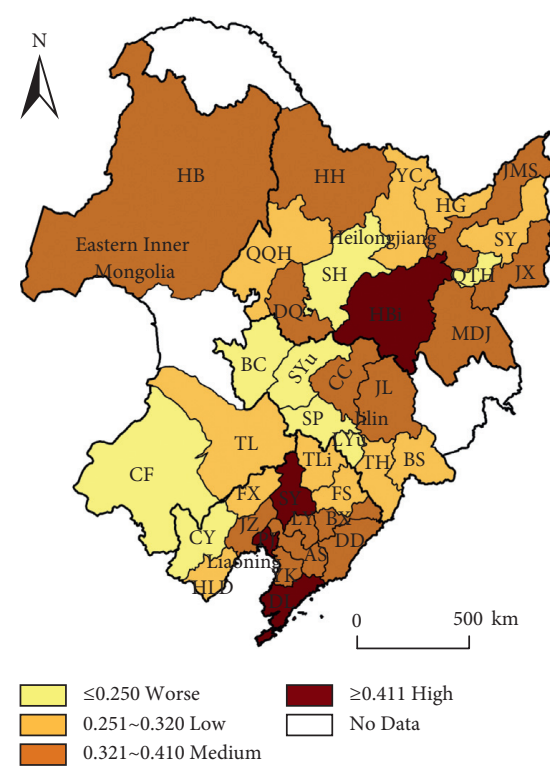

(b)

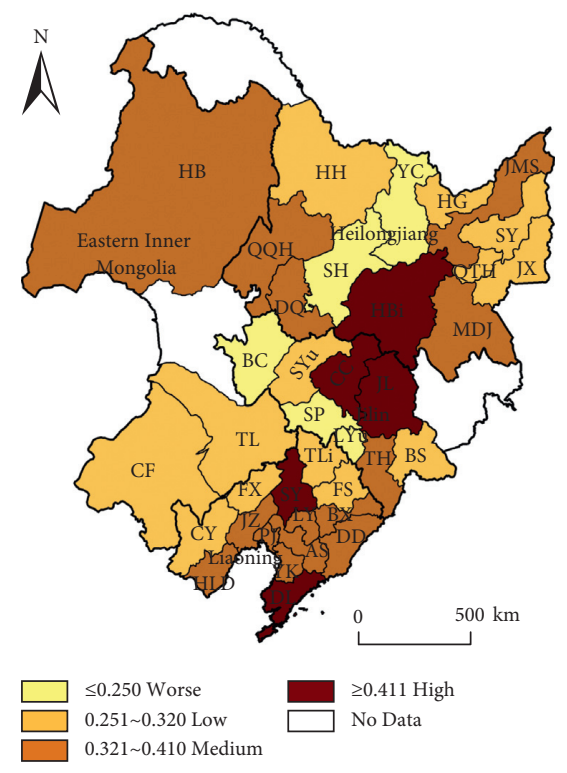

(c)

Figure 2: Map of distributions of urban economic resilience in Northeast China in 2005, 2010, and 2016.

urban economic resilience. The contribution of each subsystem in this paper can be determined according to its proportion in the urban economic resilience. The specific algorithm that we used is the entropy method (Section 3.3.2).

\subsection{Overall Characteristics of Subsystems' Contributions.} According to the average values of subsystem weight (Table 3), it is clear that urban economic resilience in the rust belt of China was significantly contributed by the subsystems of diversity and trends of development, with weights of 0.214 and 0.216 , respectively. Among the five subsystems, the system of diversity made the largest contribution to Harbin's economic resilience, with a weight of 0.336 , and the smallest contribution to Yichun's economic resilience, with a weight of 0.143 . The subsystem of capabilities related to revenue and expenditure made the largest contribution to Benxi's economic resilience, with a weight of 0.273 , and the smallest contribution to Dandong's economic resilience, with a weight of 0.124 . The innovation environment subsystem made the largest contribution to Suihua's economic resilience, with a weight of 0.370 , and the smallest contribution to Harbin, with a weight of 0.130 . The subsystem of trends in development made the largest contribution to Chifeng's economic resilience, with a weight of 0.357 , and the smallest contribution to Shenyang, with a weight of 0.135 . The openness subsystem made the largest contribution to Heihe's economic resilience, with a weight of 0.306, and the smallest contribution to Anshan's economic resilience (a weight of 0.124 ).

5.2. Spatial Mapping of Subsystem's Contribution. We applied ArcGIS to the classification of contributions of each subsystem. Four levels were grouped: low, medium, relatively high, and high. The diversity subsystem made the relatively high and high contribution to urban economic resilience in 18 cities, and these cities were concentrated in Liaoning Province (Figure 3(a)). The capability subsystem related to revenue and expenditure made the relatively high and high contribution to urban economic resilience in five cities, but these cities were scattered in space (Figure 3(b)). The innovation environment system made the relatively high and high contribution to urban economic resilience in 14 cities, and these cities were concentrated in central and eastern Heilongjiang Province (Figure 3(c)). The trend of development system made the relatively high and high contribution to urban economic resilience in 18 cities, and these cities were mainly in western Heilongjiang Province, southern Liaoning Province, and eastern Inner Mongolia Autonomous Region (Figure 3(d)). The openness system made the relatively high and high contribution to urban economic resilience in 11 cities, and these cities were concentrated in northern Heilongjiang Province, northern Jilin Province, and central Liaoning Province (Figure 3(e)).

5.3. Major Factors Contributing Economic Resilience of Different Types of Cities. Cities in the rust belt in China can be divided into four types according to development: comprehensive economic cities, resource-based and old industrial cities, coastal cities, and agricultural cities. The cities can be divided into large, medium-sized, and small according to their urban population (Table 4). Considering the weights of the subsystems at the relatively high and high levels as the factor that makes a greater contribution to urban economic resilience, the results are summarized as follows: comprehensive economic cities were mainly large cities and were significantly contributed by the subsystem of diversity. Resource-based and old industrial cities as a whole were significantly contributed by the subsystem of innovation environment (seven cities). In terms of scale, large cities were contributed by the diversity subsystem, medium-sized 
TABLE 3: Weights of the contribution of each subsystem on the economic resilience of cities in Northeast China.

\begin{tabular}{|c|c|c|c|c|c|c|}
\hline City & $\begin{array}{l}\text { Diversity } \\
\text { system }\end{array}$ & $\begin{array}{c}\text { Capabilities related to revenue and } \\
\text { expenditure system }\end{array}$ & $\begin{array}{c}\text { Innovation } \\
\text { environment system }\end{array}$ & $\begin{array}{c}\text { Trend of development } \\
\text { system }\end{array}$ & $\begin{array}{c}\text { Openness } \\
\text { system }\end{array}$ & Total \\
\hline Chifeng & 0.148 & 0.167 & 0.178 & 0.357 & 0.150 & 1 \\
\hline Tongliao & 0.150 & 0.150 & 0.233 & 0.315 & 0.151 & 1 \\
\hline Hulun Buir & 0.186 & 0.227 & 0.187 & 0.208 & 0.192 & 1 \\
\hline Shenyang & 0.280 & 0.148 & 0.138 & 0.135 & 0.299 & 1 \\
\hline Dalian & 0.309 & 0.140 & 0.137 & 0.262 & 0.152 & 1 \\
\hline Anshan & 0.264 & 0.171 & 0.301 & 0.140 & 0.124 & 1 \\
\hline Fushun & 0.207 & 0.135 & 0.151 & 0.346 & 0.161 & 1 \\
\hline Benxi & 0.243 & 0.273 & 0.148 & 0.148 & 0.188 & 1 \\
\hline Dandong & 0.292 & 0.124 & 0.152 & 0.267 & 0.164 & 1 \\
\hline Jinzhou & 0.212 & 0.147 & 0.144 & 0.353 & 0.144 & 1 \\
\hline Yingkou & 0.324 & 0.126 & 0.156 & 0.237 & 0.158 & 1 \\
\hline Fuxin & 0.254 & 0.133 & 0.207 & 0.138 & 0.267 & 1 \\
\hline Liaoyang & 0.285 & 0.174 & 0.171 & 0.172 & 0.198 & 1 \\
\hline Panjin & 0.191 & 0.198 & 0.225 & 0.192 & 0.195 & 1 \\
\hline Tieling & 0.203 & 0.178 & 0.256 & 0.192 & 0.170 & 1 \\
\hline Chaoyang & 0.301 & 0.172 & 0.178 & 0.185 & 0.164 & 1 \\
\hline Huludao & 0.227 & 0.181 & 0.195 & 0.220 & 0.177 & 1 \\
\hline Changchun & 0.212 & 0.181 & 0.158 & 0.246 & 0.204 & 1 \\
\hline Jilin & 0.251 & 0.140 & 0.145 & 0.200 & 0.264 & 1 \\
\hline Siping & 0.151 & 0.151 & 0.318 & 0.182 & 0.199 & 1 \\
\hline Liaoyuan & 0.176 & 0.176 & 0.177 & 0.199 & 0.272 & 1 \\
\hline Tonghua & 0.192 & 0.198 & 0.220 & 0.192 & 0.198 & 1 \\
\hline Baishan & 0.184 & 0.184 & 0.187 & 0.261 & 0.183 & 1 \\
\hline Songyuan & 0.191 & 0.199 & 0.195 & 0.225 & 0.191 & 1 \\
\hline Baicheng & 0.156 & 0.156 & 0.165 & 0.353 & 0.171 & 1 \\
\hline Harbin & 0.336 & 0.170 & 0.130 & 0.188 & 0.176 & 1 \\
\hline Qiqihar & 0.190 & 0.198 & 0.194 & 0.221 & 0.197 & 1 \\
\hline Jixi & 0.166 & 0.198 & 0.304 & 0.166 & 0.166 & 1 \\
\hline Hegang & 0.172 & 0.201 & 0.252 & 0.202 & 0.173 & 1 \\
\hline Shuangyashan & 0.211 & 0.173 & 0.170 & 0.170 & 0.275 & 1 \\
\hline Daqing & 0.189 & 0.208 & 0.168 & 0.221 & 0.215 & 1 \\
\hline Yichun & 0.143 & 0.152 & 0.268 & 0.139 & 0.299 & 1 \\
\hline Jiamusi & 0.168 & 0.173 & 0.266 & 0.175 & 0.218 & 1 \\
\hline Qitaihe & 0.261 & 0.128 & 0.248 & 0.135 & 0.228 & 1 \\
\hline Mudanjiang & 0.179 & 0.201 & 0.230 & 0.218 & 0.172 & 1 \\
\hline Heihe & 0.153 & 0.140 & 0.132 & 0.269 & 0.306 & 1 \\
\hline Suihua & 0.153 & 0.157 & 0.370 & 0.159 & 0.161 & 1 \\
\hline Average value & 0.214 & 0.171 & 0.201 & 0.216 & 0.198 & 1 \\
\hline
\end{tabular}

Note: to make the data clearer, values in the table were all rounded to three decimal places.

cities were contributed by the innovation environment subsystem, and small cities were contributed by the developmental trends system. Coastal cities as a whole were greatly contributed by the diversity subsystem (five cities) and subsystem of developmental trends (five cities), no matter whether large cities, medium-sized cities, or small cities. Agricultural cities were mainly small and mediumsized cities and were greatly contributed by the subsystem of developmental trends (four cities). In terms of scale, medium-sized cities were contributed by the innovation environment subsystem, and small cities were contributed by the developmental trends system.

\subsection{Promote Suggestions}

5.4.1. Promote Diversity. The diversity subsystem can be improved mainly by enhancing industrial diversity and the ability of industries to transform and upgrade. Industrial diversity can be improved by extending the industry chain and promoting the diversity of regional enterprises. The extension of the industry chain can reinforce the connection between upstream and downstream enterprises, promote industry gathering in the region, and provide a basis for resource sharing between industries. The diversity of regional enterprises can allow different types of enterprises and talents to coexist, alleviate the problems posed by the large proportion of state-owned enterprises in Northeast China, and provide more employment opportunities and economic income.

The system of diversity made the largest contribution to the urban economic resilience of comprehensive cities (Dalian, Changchun, Shenyang, and Harbin) and some coastal cities (Dandong, Jinzhou, Yingkou, and Huludao). These cities can take the following specific measures to improve their economic resilience. In terms of extending the industrial chain, it can be achieved by introducing upstream and downstream industries. Introduced industries need to 


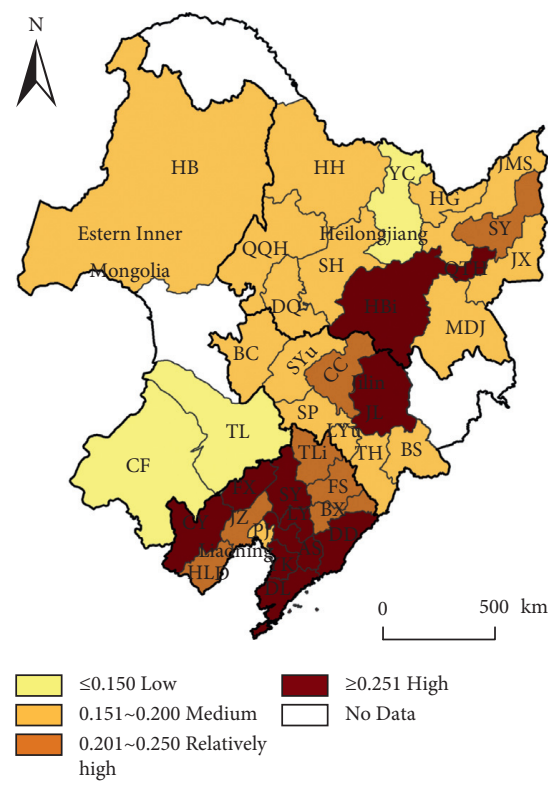

(a)

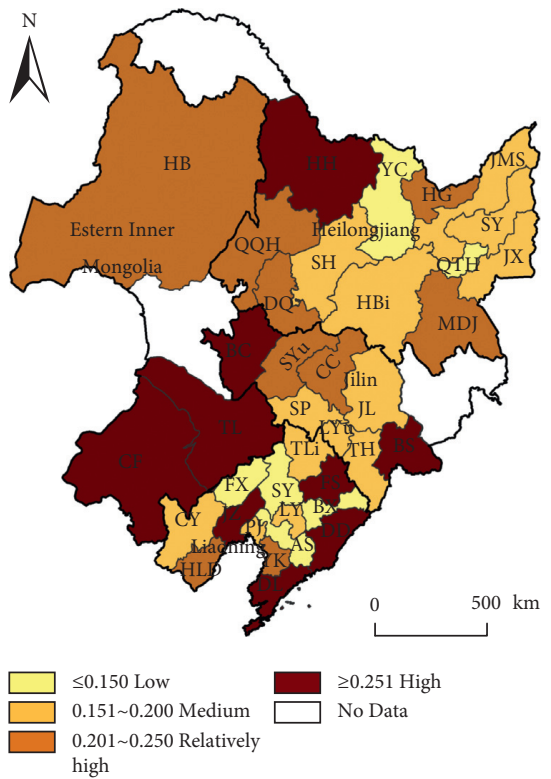

(d)

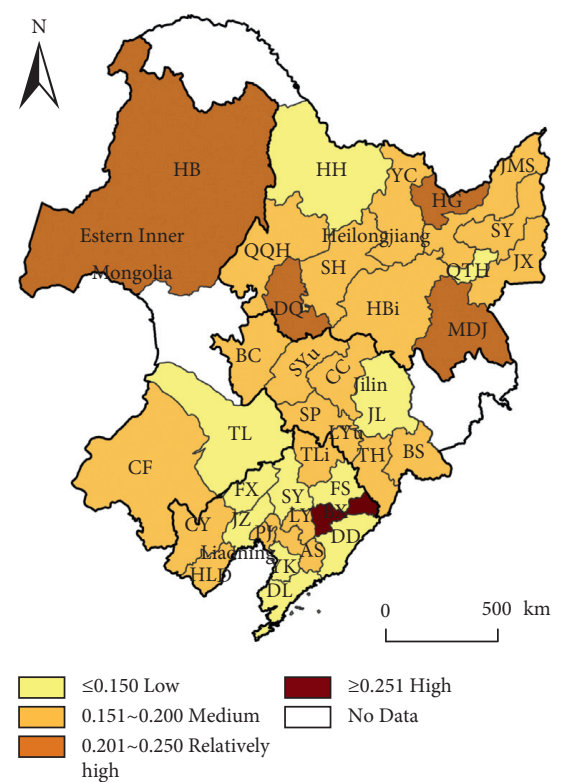

(b)

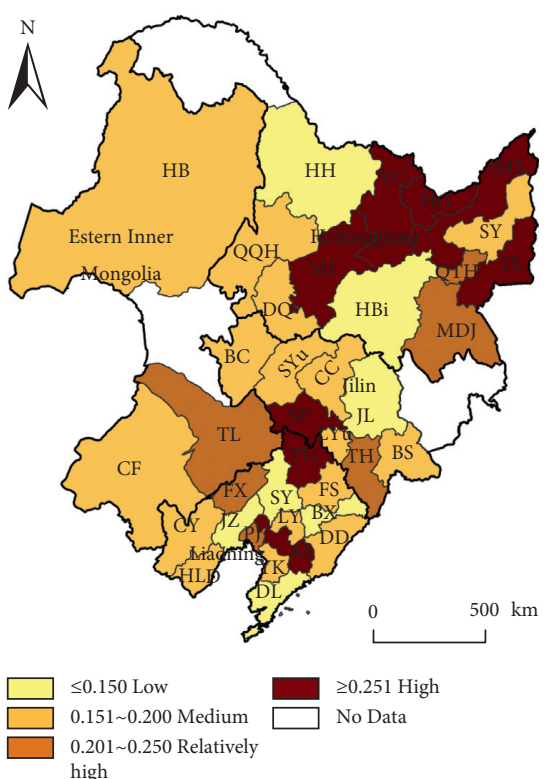

(c)

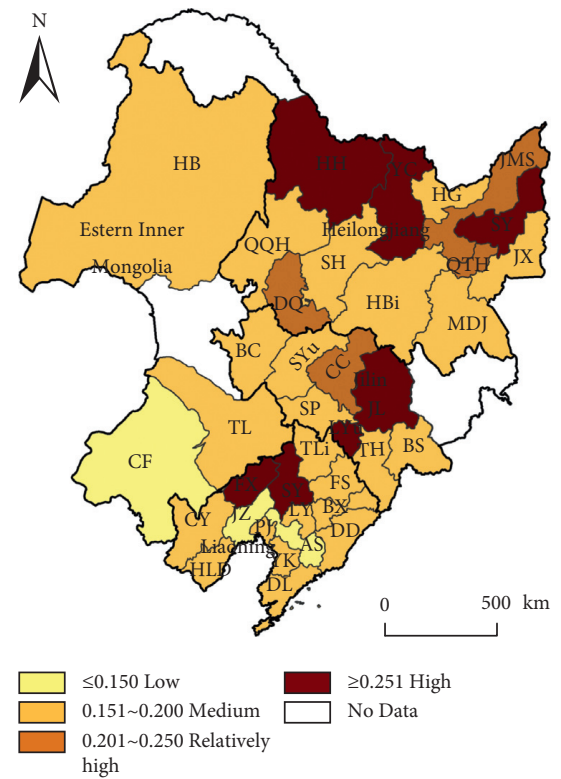

(e)

Figure 3: Spatial distribution of the degree of contribution of subsystems on urban economic resilience. (a) Contribution degree of the diversity system. (b) Contribution degree of capabilities related to revenue and expenditure system. (c) Contribution degree of the innovation environment system. (d) Contribution degree of the trend development system. (e) Contribution degree of the openness system.

TABLE 4: Weight ratings of subsystems contributing economic resilience for different types and scales of cities.

\begin{tabular}{|c|c|c|c|c|c|c|c|}
\hline Type & Scale & City & $\begin{array}{c}\text { Diversity } \\
\text { system level }\end{array}$ & $\begin{array}{c}\text { Capabilities related } \\
\text { to revenue and } \\
\text { expenditure system } \\
\text { level }\end{array}$ & $\begin{array}{c}\text { Innovation } \\
\text { environment } \\
\text { system level }\end{array}$ & $\begin{array}{c}\text { Trend of } \\
\text { development } \\
\text { system level }\end{array}$ & $\begin{array}{c}\text { Openness } \\
\text { system level }\end{array}$ \\
\hline $\begin{array}{l}\text { Comprehensive } \\
\text { economic city }\end{array}$ & Large city & $\begin{array}{c}\text { Dalian } \\
\text { Changchun } \\
\text { Shenyang } \\
\text { Harbin }\end{array}$ & $\begin{array}{l}\text { High } \\
\text { R-high } \\
\text { High } \\
\text { High }\end{array}$ & $\begin{array}{c}\text { Low } \\
\text { Medium } \\
\text { Low } \\
\text { Medium }\end{array}$ & $\begin{array}{l}\text { Low } \\
\text { Medium } \\
\text { Low } \\
\text { Low }\end{array}$ & $\begin{array}{l}\text { High } \\
\text { R-high } \\
\text { Low } \\
\text { Medium }\end{array}$ & $\begin{array}{l}\text { Medium } \\
\text { R-high } \\
\text { High } \\
\text { Medium }\end{array}$ \\
\hline
\end{tabular}


TABLE 4: Continued.

\begin{tabular}{|c|c|c|c|c|c|c|c|}
\hline Type & Scale & City & $\begin{array}{c}\text { Diversity } \\
\text { system level }\end{array}$ & $\begin{array}{c}\text { Capabilities related } \\
\text { to revenue and } \\
\text { expenditure system } \\
\text { level }\end{array}$ & $\begin{array}{l}\text { Innovation } \\
\text { environment } \\
\text { system level }\end{array}$ & $\begin{array}{c}\text { Trend of } \\
\text { development } \\
\text { system level }\end{array}$ & $\begin{array}{l}\text { Openness } \\
\text { system level }\end{array}$ \\
\hline \multirow{15}{*}{$\begin{array}{l}\text { Resource-based and } \\
\text { old industrial city }\end{array}$} & \multirow{4}{*}{ Large city } & Anshan & High & Medium & High & Low & Low \\
\hline & & Fushun & R-high & Low & Medium & High & Medium \\
\hline & & Jilin & High & Low & Low & Medium & High \\
\hline & & Daqing & Medium & R-high & Medium & R-high & R-high \\
\hline & \multirow{7}{*}{$\begin{array}{l}\text { Medium- } \\
\text { sized city }\end{array}$} & Chifeng & Low & Medium & Medium & High & Low \\
\hline & & Benxi & R-high & High & Low & Low & Medium \\
\hline & & Fuxin & High & Low & R-high & Low & High \\
\hline & & Panjin & Medium & Medium & R-high & Medium & Medium \\
\hline & & Jixi & Medium & Medium & High & Medium & Medium \\
\hline & & Yichun & Low & Medium & High & Low & High \\
\hline & & Mudanjiang & Medium & R-high & R-high & R-high & Medium \\
\hline & \multirow{4}{*}{ Small city } & Huludao & R-high & Medium & Medium & R-high & Medium \\
\hline & & Liaoyuan & Medium & Medium & Medium & Medium & High \\
\hline & & Tonghua & Medium & Medium & R-high & Medium & Medium \\
\hline & & Baishan & Medium & Medium & Medium & High & Medium \\
\hline \multirow{6}{*}{ Coastal cities } & \multirow[t]{2}{*}{ Large city } & Dalian & High & Low & Low & High & Medium \\
\hline & & Panjin & Medium & Medium & R-high & Medium & Medium \\
\hline & \multirow{3}{*}{$\begin{array}{l}\text { Medium- } \\
\text { sized city }\end{array}$} & Dandong & High & Low & Medium & High & Medium \\
\hline & & Jinzhou & R-high & Low & Low & High & Low \\
\hline & & Yingkou & High & Low & Medium & R-high & Medium \\
\hline & Small city & Huludao & R-high & Medium & Medium & R-high & Medium \\
\hline \multirow{6}{*}{ Agricultural city } & \multirow{3}{*}{$\begin{array}{l}\text { Medium- } \\
\text { sized city }\end{array}$} & Panjin & Medium & Medium & R-high & Medium & Medium \\
\hline & & Siping & Medium & Medium & High & Medium & Medium \\
\hline & & Hulun Buir & Medium & R-high & Medium & R-high & Medium \\
\hline & \multirow{3}{*}{ Small city } & Songyuan & Medium & Medium & Medium & R-high & Medium \\
\hline & & Baicheng & Medium & Medium & Medium & High & Medium \\
\hline & & Heihe & Medium & Low & Low & High & High \\
\hline
\end{tabular}

Note. (1) According to the Notice on Adjusting the Standard of City Scale Division, the standard for the scale for cities was based on the population of their urban areas. Small cities (fewer than 500,000people), medium-sized cities (500,000-1 million), large cities (1 million-5 million), megacities (5 million-10 million), and supercities (over 10 million) ("more than" includes the number itself, and "less than" does not include it). (2) R-high in the table refers to relatively high.

be related to the existing industries. On the one hand, this way can provide more diverse employment opportunities and increase economic income. On the other hand, this way can promote the agglomeration of enterprises within the city and make the connection between upstream and downstream enterprises and existing enterprises closer, such as face-to-face contact with key personnel and timely information acquisition. In terms of promoting the transformation and upgrading of industries, it can be carried out in stages: first, cities can take the lead in introducing enterprises engaged in basic industries, including technology, transportation, energy, raw materials, and other industrial types of enterprises. This can reduce the unit production costs of other enterprises and improve economic benefits. Next, cities need to introduce emerging enterprises. Cities should first understand the supply and demand of labor in existing industries and then selectively introduce new enterprises according to the existing employment structure, thereby promoting the stable development of the urban economy.

5.4.2. Promote Capabilities Related to Revenue and Expenditure. The system of capabilities related to revenue and expenditure mainly includes micro- and macrolevels.
And it made the largest contribution to the urban economic resilience of Benxi, Hulun Buir, Daqing, Mudanjiang, and Hegang. These cities can take the following specific measures to improve their economic resilience. At the microlevel, the abovementioned cities can increase the income of urban residents by increasing the wages of employees and improving the wage protection system. For example, by increasing the adjustment of the increase in wages of employees, improving and implementing the minimum wage system, and promoting enterprises to establish a collective wage bargaining system to improve the income and expenditure capacity of the urban economy. At the same time, cities should improve measures conducive to expanding consumption, for example, by implementing low fees for public welfare places such as museums, memorials, exhibition halls, and other public welfare places to broaden the scope of consumption. At the macrolevel, first, cities should play the role of tax macrocontrol. This is mainly through two ways: "tax increase" and "tax reduce." For example, when the economy is booming, the national income level and consumption capacity will increase, and tax increase can prevent the effect of excessive economic expansion; while the economy is in recession, the national 
income level and consumption power will decrease, and tax reduce can attract investment. Second, cities can increase fiscal macrocontrol, mainly by adjusting the structure of fiscal expenditures, such as increasing fiscal spending on science and education, culture, public health, and other social undertakings, thus promoting scientific and technological progress, developing the environmental protection industry, and promoting the transformation of socioeconomic development.

\subsubsection{Promote Innovation Environment. The innovation} environment system can provide an impetus for innovative activities. And it made the largest contribution to the urban economic resilience of resource-based and old industrial cities (Anshan, Fuxin, Panjin, Jixi, Yichun, Mudanjiang, and Tonghua). These cities can take the following specific measures to improve their economic resilience. First, local governments should ensure equitable access to innovation resources. Specifically, it can be achieved by cultivating and introducing high-tech enterprises, high-level universities, and scientific research institutions with high innovation ability. Second, full play should be given to the leading role of entrepreneurs and stimulate their enthusiasm for innovation. At the same time, enterprises must establish a fair reward mechanism that can help distribute dividends to talents who made important contributions to innovation. Specifically, enterprises can implement equity incentive and dividend incentive for innovative talents, so that entrepreneurs can get more benefits and spiritual incentives for their innovative activities. Third, we must focus on cultivating and attracting all types of talent and formulate policies that promote the mobility and introduction of talent, for example, settling down for talents and solving problems such as children's enrollment and spouse employment. Fourth, we need to strengthen domestic and international collaborative innovation and make full and effective use of resources and markets for foreign innovation, such as strengthening trade cooperation with neighboring countries, in order to broaden urban innovative development path.

5.4.4. Promote Developmental Trends. The system of developmental trends includes two aspects: economic and social development. A good urban economic development trend is a necessary condition for improving the ability of the urban economic system to resist uncertain risks and promoting the stable development of the urban economy. The developmental trend system made the largest contribution to the urban economic resilience of agricultural cities (Hulun Buir, Songyuan, Baicheng, and Heihe) and some coastal cities (Dalian, Panjin, Dandong, Jinzhou, Yingkou, and Huludao). The following measures can be taken to maintain a good trend of urban economic development for the above cities: the first is to adjust the economic structure to promote growth. This is mainly through adjusting the industrial structure to bring the urban economic development of the Northeast region to a new level. Northeast China has a large number of old industrial base cities and resource- dependent cities. Thus, adjusting the industrial structure can promote rapid urban economic growth. Second, we need to pay attention to population-related issues, adjust social distribution, and solve employment problems. Population aging is a problem in the economic development of cities in Northeast China. It can be alleviated through such measures as adjusting population policies, improving the population structure, increasing the working age range of the labor force, encouraging older people to continue working, and improving the social security system. Third, we need to protect the resources and the environment to improve the living standards of residents. The available resource reserves need to be protected. At the same time, more attention should be given to environmental issues. The protection of resources and the environment can guarantee an improvement in the quality of life. For example, cities can encourage the development of new pollution-free enterprises while adjusting the industrial structure and encourage the use of clean production materials and technologies for existing industrial enterprises.

5.4.5. Promote Openness. The openness system includes two aspects: openness to foreign and domestic trade. And it made the largest contribution to the urban economic resilience of Heihe, Yichun, Shenyang, Shuangyashan, Liaoyuan, and other cities. The following strategies can be adopted in enhancing the openness of foreign trade for above cities: first of all, the business environment should be improved to enhance the intensity of investment attraction, because the quality of business environment directly affects the intensity of investment attraction. In recent years, one of the reasons for the slow economic development of cities in Northeast China is the lack of a good business environment, which affects the enthusiasm of foreign investment. Therefore, the government of each city should create a stable institutional environment to ensure the legitimate rights of investors. For example, the government can actively promote the openness of government affairs to establish its reputation, curb the phenomenon of arbitrary fees to reduce the burden of foreign enterprises, and standardize and simplify all kinds of examination and approval, licensing, and registration procedures to create a good business environment. Secondly, cities can further develop the northeast Asian market by attracting the investment of multinational corporations, so as to improve the level of urban import and export trade. At present, the proportion of investment by multinational companies in cities in the Northeast is relatively small. Therefore, cities should highlight their characteristics and focus on attracting the investment of large foreign transnational corporations, to improve the openness of domestic trade. Due to the cost and convenience of transportation directly affect the possibility of trade between cities, they can start by improving infrastructure and promoting the construction of a comprehensive regional transportation network. Specific measures include speeding up the construction of dead-end roads in each province, and speeding up the construction of highspeed rail between cities. 


\section{Conclusion and Discussion}

\subsection{Conclusions}

6.1.1. Forming a Comprehensive Urban Economic Resilience Measurement Model. Based on the results of this research, the urban economic resilience system is mainly contributed by the five subsystems of urban economic diversity, capabilities related to revenue and expenditure, innovation environment, trends of development, and openness. We constructed an index system for urban economic resilience in Northeast China based on certain principles and index selection methods.

6.1.2. Urban Economic Resilience in Northeast China Has Gradually Increased over Time. In terms of time, the urban economic resilience of cities in Northeast China gradually increased from 2005 to 2016. The growth was small in 2005-2010 and large in 2010-2016. From 2005 to 2016, Dalian was the most resilient city and Suihua was the least, and their maximum and minimum values increased year by year. In terms of spatial distribution, urban economic resilience in Northeast China showed a gradient differentiation characteristic of "high in the east and low in the west," and the economic resilience of coastal cities was higher than that of inland cities.

6.1.3. The Most Contributing Factors Are Different for Different Types of Cities. Judging from the average values of the weights of the various subsystems, urban economic resilience in Northeast China is greatly contributed by the systems of diversity and developmental trends, with weights of 0.214 and 0.216 , respectively. The economic resilience of comprehensive cities was mainly contributed by the diversity system, and that of resource-based and old industrial cities was mainly contributed by the systems of innovation environment systems. The economic resilience of coastal cities was mainly contributed by the systems of diversity and developmental trends, and that of agricultural cities was mainly contributed by the developmental trends system. Different types of cities should enhance their economic resilience based on the factors contributing to their economic systems.

6.2. Discussion. The results of this paper have guiding significance for the sustainable development of urban economy in Northeast China. Compared with the urban resilience index system established in the existing studies $[27,28,37,38]$, the index system in this paper is specifically applied to the field of urban economic resilience, and it is more detailed. And taking into account the actual situation of the development of Northeast China, we have taken the level of industrial diversification and its transformation and upgrading ability into account when constructing the index system. Therefore, the index system is in line with the actual economic development in Northeast China and can be used as a reference for future research on urban economic resilience. Moreover, different from the existing economic resilience research $[40,47]$, we subdivided the urban types in the study area. Therefore, this study not only enriches the research on the index system of urban economic resilience in developing countries but also diversifies the types of cities studied.

Although we have made some contributions to the study of urban economic resilience, there are still some areas that need to be improved: first, few studies have empirically considered the urban economic resilience of cases in China, and theoretical research is relatively scarce as well. Therefore, some factors were not taken into account here when constructing the index system of urban economic resilience in Northeast China, especially subjective factors such as economic policies. In future research, we intend to improve the index system for the evaluation of urban economic resilience from different perspectives. Second, this paper studied economic resilience at the city scale. No comparative analysis of economic resilience was provided between scales. The scale of research can be changed for further research. Finally, we did not consider the interaction between contributive factors in the context of urban economic resilience in Northeast China. A correlation test of these factors will be an important subject for research in the future.

\section{Data Availability}

The data were drawn mainly from the China City Statistical Yearbook, China City Construction Statistical Yearbook, Regional Economic Statistical Yearbook, the statistical yearbooks of the relevant provinces and cities, economic census yearbooks, and statistical bulletins.

\section{Conflicts of Interest}

The authors declare that there are no conflicts of interest regarding the publication of this paper.

\section{Acknowledgments}

This research was supported by the Philosophy and Social Science Foundation of China, no. 16BJY039.

\section{References}

[1] T. Li, "New progress in study on resilient cities," Urban Planning International, vol. 32, no. 5, pp. 15-25, 2017, in Chinese.

[2] L. Chen, X. Zhu, and J. Sun, "The basic concept, mechanism and planning ideas of resilient cities," Modern Urban Research, vol. 9, pp. 18-24, 2017, in Chinese.

[3] X. Hu and C. Yang, "Building a role model for rust belt cities? Fuxin's economic revitalization in question," Cities, vol. 72, pp. 245-251, 2018.

[4] L. Zhao, W. Wang, Y. Zhang, R. Li, and D. Wu, "The spatiotemporal evolution about urban vulnerability on the Northeast region since Northeast revitalization," Economic Geography, vol. 34, no. 12, pp. 69-77, 2014, in Chinese.

[5] J. Sun and X. Sun, "Research progress of regional economic resilience and exploration of its application in China," Economic Geography, vol. 37, pp. 1-9, 2014, in Chinese. 
[6] C. S. Holling, "Resilience and stability of ecological systems," Annual Review of Ecology and Systematics, vol. 4, no. 4, pp. 1-23, 1973.

[7] W. N. Adger, "Social and ecological resilience: are they related?" Progress in Human Geography, vol. 24, no. 3, pp. 347-364, 2000.

[8] A. Rose, "Economic resilience to natural and man-made disasters: multidisciplinary origins and contextual dimensions," Environmental Hazards, vol. 7, no. 4, pp. 383-398, 2007.

[9] N. J. Wood, C. G. Burton, and S. L. Cutter, "Community variations in social vulnerability to Cascadia-related tsunamis in the U.S. Pacific Northwest," Natural Hazards, vol. 52, no. 2, pp. 369-389, 2010.

[10] F. Landry, J. Dupras, and C. Messier, "Convergence of urban forest and socio-economic indicators of resilience: a study of environmental inequality in four major cities in eastern Canada," Landscape and Urban Planning, vol. 202, 2020.

[11] S. T. A. Pickett, M. L. Cadenasso, and J. M. Grove, "Resilient cities: meaning, models, and metaphor for integrating the ecological, socio-economic, and planning realms," Landscape and Urban Planning, vol. 69, no. 4, pp. 369-384, 2004.

[12] R. Leichenko, "Climate change and urban resilience," Current Opinion in Environmental Sustainability, vol. 3, no. 3, pp. 164-168, 2011.

[13] J. Ahern, "From fail-safe to safe-to-fail: sustainability and resilience in the new urban world," Landscape and Urban Planning, vol. 100, no. 4, pp. 341-343, 2011.

[14] P. Lu and D. Stead, "Understanding the notion of resilience in spatial planning: a case study of Rotterdam, The Netherlands," Cities, vol. 35, no. 4, pp. 200-212, 2013.

[15] M. Thornbush, O. Golubchikov, and S. Bouzarovski, "Sustainable cities targeted by combined mitigation-adaptation efforts for future-proofing," Sustainable Cities and Society, vol. 9, pp. 1-9, 2013.

[16] S. Meerow and J. P. Newell, "Spatial planning for multifunctional green infrastructure: growing resilience in Detroit," Landscape and Urban Planning, vol. 159, pp. 62-75, 2017.

[17] S. Tyler and M. Moench, "A framework for urban climate resilience," Climate \& Development, vol. 4, no. 4, pp. 311-326, 2012.

[18] K. C. Desouza and T. H. Flanery, "Designing, planning, and managing resilient cities: a conceptual framework," Cities, vol. 35, pp. 89-99, 2013.

[19] M. Suárez, E. Gómez-Baggethun, J. Benayas, and D. Tilbury, "Towards an urban resilience index: a case study in 50 Spanish cities," Sustainability, vol. 8, no. 8, p. 774, 2016.

[20] D. Zhao, B. Shi, Y. Chen, C. Chen, and P. Lei, "Effect of collaborative management on enhancement mechanism of urban resilience," Management Review, vol. 8, pp. 207-214, 2016.

[21] R. Hassink, "Regional resilience: a promising concept to explain differences in regional economic adaptability?" Cambridge Journal of Regions, Economy and Society, vol. 3, no. 1, pp. 45-58, 2010.

[22] R. Martin, "Regional economic resilience, hysteresis and recessionary shocks," Journal of Economic Geography, vol. 12, no. 12, pp. 1-32, 2012.

[23] R. Wink, "Regional economic resilience: policy experiences and issues in Europe," Raumforschung und Raumordnung, vol. 72, no. 2, pp. 83-84, 2014.
[24] S. Meerow, J. P. Newell, and M. Stults, "Defining urban resilience: a review," Landscape and Urban Planning, vol. 147, pp. 38-49, 2016.

[25] M. Spaans and B. Waterhout, "Building up resilience in cities worldwide - rotterdam as participant in the 100 resilient cities programme," Cities, vol. 61, pp. 109-116, 2017.

[26] J. Simmie and R. Martin, "The economic resilience of regions: towards an evolutionary approach," Cambridge Journal of Regions, Economy and Society, vol. 3, no. 1, pp. 27-43, 2010.

[27] L. Oxborrow and C. Brindley, "Regional resilience in recessionary times: a case study of the East Midlands," International Journal of Retail \& Distribution Management, vol. 40, no. 11, pp. 882-899, 2012.

[28] B. Fingleton, H. Garretsen, and R. Martin, "Recessionary shocks and regional employment: evidence on the resilience of U.K. regions," Journal of Regional Science, vol. 52, no. 1, pp. 109-133, 2012.

[29] A. Sharifi, "Resilient urban forms: a macro-scale analysis," Cities, vol. 85, pp. 1-14, 2019.

[30] J. R. Holm and C. R. Østergaard, "Regional employment growth, shocks and regional industrial resilience: a quantitative analysis of the Danish ICT sector," Regional Studies, vol. 49, no. 1, pp. 95-112, 2015.

[31] R. Capello, A. Caragliu, and U. Fratesi, "Spatial heterogeneity in the costs of the economic crisis in Europe: are cities sources of regional resilience?" Journal of Economic Geography, vol. 15, no. 5, pp. 951-972, 2015.

[32] Q. Xie, "Enlightenment of resilient city construction policy in developed country," Scientific Decision Making, vol. 24, no. 4, pp. 60-75, 2017, in Chinese.

[33] K. Liu, "Emergence and theory construction of resilient planning in the background of socialist market economy: based on urban planning practice in Shenzhen (1979-2011)," City Planning Review, vol. 38, no. 11, pp. 59-64, 2014, (in Chinese).

[34] C. Xiu, Y. Wei, and Q. Wang, "“Evaluation of urban resilience of Dalian city based on the perspective of "Size-DensityMorphology" Acta Geographica Sinica, vol. 73, no. 12, pp. 2315-2328, 2018, in Chinese.

[35] Y. Chen and K. Li, "Overseas studies progress and practice exploration on resilient city: based on the perspective of public administration," Chinese Public Administration, vol. 33, no. 1, pp. 137-143, 2017, in Chinese.

[36] X. Zang and Q. Wang, "Case studies on resilience," Resilience and Urban Disasters, vol. 37, no. 22, p. 94, 2019, in Chinese.

[37] J. Liu and Z. Zeng, "The construction and empirical study of the evaluation index system of resilient city," E-Government, vol. 3, pp. 82-88, 2014, in Chinese.

[38] L. Zhou, "Resilient Cities: risk Management and indicator construction--Also discuss the international case," Journal of Beijing Administration Institute, vol. 13-20, 2016 in Chinese.

[39] X. Qi, J. Zhang, and W. Xu, "A study on the evaluation of the development of county economic resilience in zhejiang province," Zhejiang Social Sciences, vol. 5, pp. 40-46+156, 2019, in Chinese.

[40] Y. Xu and C. Wang, "Influencing factors of regional economic resilience in the 2008 financial crisis: a case study of Zhejiang and Jiangsu provinces," Progress in Geography, vol. 36, no. 8, pp. 986-994, 2017, in Chinese.

[41] X. Feng, C. Xiu, L. Bai, Y. Zhong, and Y. Wei, "Comprehensive evaluation of urban resilience based on the perspective of landscape pattern: a case study of Shenyang city," Cities, vol. 104, 2020. 
[42] H. Guan, P. Zhang, W. Liu, and J. Li, “"A comparative analysis of the economic transition process of China's old industrial cities based on evolutionary resilience theory," Acta Geographica Sinica, vol. 73, no. 4, pp. 771-783, 2018, in Chinese.

[43] L. Li, P. Zhang, J. Tan, and H. Guan, "A regional economic resilience approach to the economic revitalization process in Liaoning Old Industrial Base, China," Scientia Geographica Sinica, vol. 39, no. 1, pp. 116-124, 2019, in Chinese.

[44] M. Quan and Y. Chen, "Analysis of evaluation system \& Mode of overseas resilient city," Housing Science, vol. 39, pp. 1-6, 2019, in Chinese.

[45] S. Woolf, J. Twigg, P. Parikh, A. Karaoglou, and T. Cheaib, "Towards measurable resilience: a novel framework tool for the assessment of resilience levels in slums," International Journal of Disaster Risk Reduction, vol. 19, pp. 280-302, 2016.

[46] S. Slocum and C. Kline, "Regional resilience: opportunities, challenges and policy messages from Western North Carolina," Anatolia, vol. 25, no. 3, pp. 403-416, 2014.

[47] T. Zhang, "A study of temporal and regional characteristics of the economic resilience of the cities in jiangsu province," Journal of Wuxi Vocational Institute of Commerce, vol. 18, pp. 1-8, 2018, in Chinese. 